\title{
Genderongelijkheid in de dagbladberichtgeving over kunst en cultuur
}

\author{
Een vergelijkende studie van Frankrijk, Duitsland, Nederland en \\ de Verenigde Staten, 1955-2005
}

Pauwke Berkers, Marc Verboord \& Frank Weij

\begin{abstract}
Dit artikel behandelt de mate waarin en de manier waarop genderongelijkheid is veranderd in de dagbladberichtgeving over artistieke genres in Frankrijk, Duitsland, Nederland en de Verenigde Staten van 1955 tot 2005. Via een kwantitatieve inhoudsanalyse van twee elitekranten per land voor de jaren 1955, 1975, 1995 en 2005 zijn alle artikelen over kunst en cultuur in kaart gebracht $(n=15.379)$. Onze resultaten laten ten eerste verrassend weinig cross-nationale verschillen zien in de dagbladaandacht voor vrouwen in kunst en cultuur. Ook constateren we dat er in de afgelopen vijf decennia in geen van de onderzochte landen ook maar bij benadering gendergelijkheid is bereikt. Hoewel vrouwen ondervertegenwoordigd zijn in de dagbladberichtgeving over alle artistieke genres, vonden we duidelijke verschillen tussen genres, met name tussen architectuur (stereotypisch 'mannengenre') en moderne dans en mode (stereotypische 'vrouwengenres'). Ten vierde neemt het percentage vrouwen vooral toe in de dagbladaandacht voor in prestige gedaalde genres die behoren tot de 'hoge' cultuur. Ten slotte vonden we dat naarmate de status van het type actor toeneemt (van leken naar artistieke leiders) het aandeel vrouwen in de dagbladaandacht voor kunst en cultuur afneemt.
\end{abstract}

Trefwoorden: genderongelijkheid, kunst en cultuur, media, trends, crossnationale verschillen

\section{Inleiding}

Reeds in 1985 maakte het Amerikaanse feministische kunstcollectief Guerrilla Girls een poster getiteld 'These Critics Don't Write Enough About Women Artists'. Hierop stonden de namen van 21 kunstcritici afgebeeld met de begeleidende tekst: 'Between 1979 \& 1985, less than 20\% of the feature articles \& reviews of one-person shows by these critics were about art made by women' (Guerrilla Girls 1995: 37). In Nederland suggereerde Mirjam Westen, conservator van het Museum van Moderne Kunst in Arnhem, dat de afwezigheid van vrouwen op topposities in de beeldende kunsten (deels) samenhangt met de schaarse media-aandacht: 'Er verschijnen minder kunstrecensies van vrouwelijke kunstenaars in tijdschriften (...)' (Weijts 2006). De Duitse kunsthistoricus Wibke von Bonin stelt daarom de vraag: 'Werden also auch hierzulande bald Guerrilla Girls trouble machen?' (Von Bonin 1992). Deze bezorgdheid over het gebrek aan media-aandacht is begrijpelijk. Hoewel het aantal kunstenaars en beoefenaars van 
creatieve beroepen de afgelopen decennia sterk gestegen is (IAB 2013; INSEE 2008; NEA 1994, 2008; Statline 2013), is de kans op succes in de vorm van een stabiele, permanente carrière relatief klein (Rosen 1981). Dit onderzoek bekijkt het succes van kunstenaars via hun representatie in de media, meer in het bijzonder elitekranten, die traditioneel belangrijk zijn in het legitimeren van cultuurvormen. Kunstjournalisten verbonden aan die kranten beïnvloeden de perceptie van hun lezerspubliek en andere institutionele actoren en daarmee (deels) de carrière van de betreffende kunstenaar (Baumann 2007; Janssen 1997; Van Rees 1983).

Ondanks deze maatschappelijke relevantie is er weinig wetenschappelijk onderzoek gedaan naar structurele genderongelijkheid in de media-aandacht voor kunst en cultuur. Enerzijds richten cultuursociologen zich vaak op esthetische classificaties in kunst en cultuur, en nauwelijks op genderclassificaties (vgl. Bourdieu 1993; Berkers 2012). Onderzoek dat zich wel richt op genderongelijkheid bestudeert vaak de carrières van mannen en vrouwen binnen één artistiek genre (voornamelijk in de Verenigde Staten en het Verenigd Koninklijk), zoals film (Bielby en Bielby 1996; Lincoln en Allen 2004), televisie (Bielby en Bielby 1992), klassieke muziek (Cameron 2003; MacLeod 2001), populaire muziek (Dowd, Liddle en Blyler 2005), dans (Van Dyke 1996) of architectuur (Caven 2004). Anderzijds hebben mediasociologen geconstateerd dat genderrelaties steeds minder vaak het gevolg zijn van directe interacties tussen mannen en vrouwen en in steeds belangrijkere mate worden gemedieerd door de media. Hoewel er binnen mediastudies uitgebreid onderzoek is gedaan naar genderongelijkheid in de mediarepresentatie van populaire cultuur (film, televisie), wordt vrijwel geen aandacht besteed aan 'hoge' kunst (Gauntlett 2008). Kortom, wat ontbreekt, is een integrale trendanalyse. Naast het beschrijven - en, voor zover onze data dat toestaan, verklaren - van trends tussen 1955 en 2005 omvat deze studie een cross-nationale vergelijking tussen vier westerse democratieën (Frankrijk, Duitsland, Nederland en de Verenigde Staten) die verschillen wat betreft maatschappelijke genderongelijkheid (vgl. Janssen, Kuipers en Verboord 2008). Verschillen in maatschappelijke ongelijkheid zouden mogelijke verschillen in genderongelijkheid in dagbladberichtgeving tussen landen kunnen verklaren.

De onderzoeksvraag luidt dan ook: in welke mate en op welke manier is genderongelijkheid veranderd in de dagbladberichtgeving over kunst en cultuur voor de landen Frankrijk, Duitsland, Nederland en de Verenigde Staten, in de periode 1955-2005? We operationaliseren genderongelijkheid hoofdzakelijk als de verhouding waarmee vrouwen en mannen in kunst en cultuur voorkomen in de krant, waar mogelijk in vergelijking met hun aandeel in de populatie. Voor dit artikel is gebruik gemaakt van data die zijn verzameld in het project Cultural Classification Systems in Transition (Janssen et al. 2008). Door middel van een kwantitatieve inhoudsanalyse is alle berichtgeving over kunst en cultuur in twee elitekranten per land van vier geconstrueerde weken voor de jaren 1955, 1975, 1995 en 2005 in kaart gebracht. Aan de hand van deze data - het betreft 15.379 artikelen - wordt in dit artikel gekeken naar de dagbladaandacht voor vrouwelijke vis-à-vis mannelijke actoren (zie sectie Data en methode). 
Ten eerste nemen we de longitudinale ontwikkelingen van 1955 tot en met 2005 onder de loep binnen de geselecteerde landen. Recent onderzoek lijkt te wijzen op een trendbreuk waarbij genderongelijkheid in verschillende maatschappelijke domeinen nauwelijks nog afneemt (Cotter, Hermsen en Vanneman 2011; IMF 2013; Ridgeway 2011: 5-6). Ten tweede bestuderen we potentiële cross-nationale verschillen tussen Frankrijk, Duitsland, Nederland en de Verenigde Staten om te onderzoeken of voorgaande trends een nationaal of internationaal karakter hebben. Ten derde onderzoeken we horizontale en verticale seksesegregatie in de dagbladaandacht voor kunst en cultuur. Naast genderstereotiepe associaties verschillen artistieke genres wat betreft status van elkaar, hetgeen invloed heeft op de genderongelijkheid binnen die genres, aangezien vrouwen moeilijker toegang hebben tot statusvolle genres (Tuchman en Fortin 1984; Verboord 2012). Ten slotte wordt in dit artikel aandacht besteed aan genderongelijkheid in de (hiërarchische) statusverdeling binnen genres (Becker 1982). We onderscheiden leken, experts, producenten, uitvoerende artiesten, scheppende artiesten en artistieke leiders. Via deze analyses kunnen uitspraken worden gedaan over de ontwikkeling van vrouwenemancipatie in de kunst en cultuur, hetgeen - gegeven de symbolische status van de kunsten - relevantie heeft voor de positie van vrouwen in de samenleving als geheel.

\section{Genderongelijkheid en de rol van de media}

Genderongelijkheid omvat een samenhangend geheel van sociale praktijken waarin mannen en vrouwen als verschillend worden gedefinieerd en waarbij ongelijke relaties tussen mannen en vrouwen georganiseerd worden op basis van deze (conceptuele) verschillen (Ridgeway en Smith-Lovin 1999: 192). Opvattingen over wat een man tot man en een vrouw tot vrouw maakt zijn daarmee sociale constructies, die slechts deels gebaseerd zijn op veronderstelde lichamelijke verschillen tussen de seksen (Connell 2009: 9-11). Terwijl recente meta-analyses laten zien dat psychologische verschillen tussen mannen en vrouwen verwaarloosbaar klein zijn (Hyde 2005), blijven gedeelde culturele opvattingen over de vermeende verschillen in status en competenties tussen mannen en vrouwen - en daarmee genderongelijkheid - goeddeels bestaan (Epstein 1988; Ridgeway 2011; West en Zimmerman 1987). De media spelen in deze processen van (de)legitimatie van de (veronderstelde) verschillen tussen mannen en vrouwen - en daarmee de bevoorrechte positie van mannen - een belangrijke rol.

Dagbladen zijn belangrijk in de legitimatie en consecratie van kunstenaars en cultuurproducten (Berkers, Janssen en Verboord 2011; Janssen 1997; Van Rees 1983). Critici en recensenten vervullen enerzijds de rol van poortwachter. Zij bepalen welke werken de moeite waard zijn om überhaupt aandacht aan te besteden, waarbij commerciële overwegingen in toenemende mate een rol lijken te spelen. Anderzijds kennen zij symbolische waarde toe aan de producten en kunstenaars waaraan zij aandacht besteden (Bourdieu 1993). Eerder onderzoek richt zich voornamelijk op esthetische classificaties, dat wil zeggen, hoe critici tot een bepaald esthetisch oordeel komen, hoe zij bepalen wat 'goede' en 'slechte' kunst 
is. Echter, critici laten zich in hun keuze ook vaak leiden door buitentekstuele kenmerken, zoals gender (Berkers en Eeckelaer 2014; Schmutz en Faupel 2010; Tuchman en Fortin 1984). Aangezien de mogelijke genderongelijkheid in de mediarepresentatie deels het beeld van de lezer structureert, verschaft het een 'reële' basis al dan niet ter ondersteuning van bestaande genderopvattingen (Ridgeway 2011). In dit onderzoek richten we ons dan ook op de kwantitatieve verschillen in dagbladberichtgeving over mannelijke en vrouwelijke actoren in kunst en cultuur.

\section{Macro-ontwikkelingen in genderongelijkheid}

Ten eerste onderzoeken we longitudinale trends en mogelijke cross-nationale verschillen in de mate van dagbladaandacht voor vrouwelijke vis-à-vis mannelijke actoren in het culturele veld als geheel. Om deze verschillen en trends te duiden kijken we enerzijds naar genderongelijkheid in de culturele velden van de vier onderzochte landen (mesoniveau) en anderzijds naar macrostructurele en -culturele kenmerken van de vier onderzochte landen als geheel.

\section{Participatie van mannen en vrouwen in culturele velden}

De mate van aandacht voor vrouwen in dagbladen hangt waarschijnlijk deels samen met hun positie in de kunstwereld zelf. Hoe meer vrouwen er werkzaam zijn in de culturele velden van de onderzochte landen, hoe meer aandacht zij in de elitekranten ontvangen, zo veronderstelt een eenvoudige reflectiebenadering (Griswold 1981). Tabel 1 geeft het aandeel vrouwen weer dat werkzaam is in kunst en cultuur in Frankrijk, Duitsland, Nederland en de Verenigde Staten van 1975 tot en met 2005. We zien dat de verschillen tussen de landen relatief klein zijn. ${ }^{1}$ De participatie van vrouwen (als aandeel van het totaal aantal werkzame personen in kunst en cultuur) neemt in alle landen geleidelijk toe van ongeveer $30-35 \%$ rond 1975 naar $40-45 \%$ in de jaren negentig en $45-50 \%$ in 2005 , een patroon dat ook opgeld doet voor het aandeel vrouwen in de totale beroepsbevolking. Hoewel mannen dus gedurende de gehele periode oververtegenwoordigd zijn in de kunst en cultuur, neemt hun dominantie geleidelijk af.

Hypothese 1 (aandeel vrouwen in culturele velden)

De mate van genderongelijkheid in de berichtgeving over kunst en cultuur zal (1a) gedurende de periode 1955-2005 afnemen in alle onderzochte landen en (1b) nauwelijks cross-nationale verschillen vertonen.

\section{Macrostructurele en -culturele genderongelijkheid}

Hoewel het in theorie mogelijk is dat de dagbladberichtgeving een reflectie is van de kunstenaarspopulatie, maken de media onderdeel uit van - en geven zij vorm

1 Tabel 1 moet met enige voorzichtigheid geïnterpreteerd worden aangezien de populatie in de vier onderzochte landen op verschillende manieren gemeten is. 
Tabel 1 Aandeel vrouwen werkzaam in het culturele veld en als onderdeel totale beroepsbevolking

\begin{tabular}{|c|c|c|c|c|}
\hline & 1955* & 1975 & 1995 & 2005 \\
\hline \multicolumn{5}{|l|}{ Frankrijk } \\
\hline Le secteur culturel & - & $31 \%(1982)$ & $37 \%(1999)$ & $47 \%$ \\
\hline Totale beroepsbevolking & - & $40 \%(1982)$ & $45 \%(1999)$ & $46 \%$ \\
\hline \multicolumn{5}{|l|}{ Duitsland } \\
\hline $\begin{array}{l}\text { Künstlerlinnen und zugeordnete Berufe } \\
\text { (excl. Publizisten) }\end{array}$ & - & $33 \%(1970) * *$ & $41 \%(1999)$ & $43 \%$ \\
\hline Totale beroepsbevolking & - & $37 \%(1970)$ & $44 \%$ (1999) & $45 \%$ \\
\hline \multicolumn{5}{|l|}{ Nederland } \\
\hline Kunst, cultuur en loterij & - & $37 \%$ & $47 \%$ & $51 \%$ \\
\hline Totale beroepsbevolking & - & $32 \%$ & $42 \%$ & $46 \%$ \\
\hline \multicolumn{5}{|l|}{ Verenigde Staten } \\
\hline Artist occupations & - & $31 \%(1970)$ & $44 \%(1990)$ & $46 \%$ \\
\hline Totale beroepsbevolking & - & $38 \%(1970)$ & $46 \%(1990)$ & $46 \%$ \\
\hline
\end{tabular}

* Data over 1955 zijn niet beschikbaar

** Data over 1970 betreffen West Duitsland

Bronnen:

Frankrijk: Cléron en Patureau (2007), INSEE (2009); Duitsland: Federal Reserve Economic Data (20I3), Fohrbeck en Wiesand (1975), IAB (20I3); Nederland: CBS (2007), Statline (2013); Verenigde Staten: NEA $(1994,2008)$

aan - de praktijken en opvattingen over genderongelijkheid in een bepaalde samenleving. Er bestaan verschillende maten om genderongelijkheid op nationaal niveau te meten, maar vergelijkbare gegevens in de vier onderzochte landen over een periode van vijftig jaar zijn niet beschikbaar. Ten eerste hanteren de Verenigde Naties (2011) sinds 1995 de zogenaamde Gender Inequality Index (GII) (0-1) om macrostructurele genderongelijkheid te meten, welke bestaat uit drie dimensies: gezondheid (moedersterfte en vruchtbaarheid), macht (vertegenwoordiging in het parlement en opleidingsniveau) en arbeid (vrouwenparticipatie). Gegevens uit deze index laten zien dat de genderongelijkheidsscore in de Verenigde Staten hoger is en toeneemt, respectievelijk van 0,284 (1995) naar 0,311 (2005), ten opzichte van een daling van 0,184 naar 0,105 in Duitsland, van 0,146 naar 0,139 in Frankrijk en van 0,095 naar 0,077 in Nederland. Ten tweede heeft Hofstede (1998) een macroculturele index ontwikkeld. Deze 'masculinity' index (MAS) (0-100) geeft de mate aan waarin genderrollen in een bepaalde samenleving gescheiden zijn. Een hoge score betekent dat van mannen verwacht wordt dat ze assertief, stoer en gericht op materieel succes zijn. Vrouwen daarentegen behoren zich bescheiden en vriendelijk op te stellen en zich te oriënteren op kwaliteit van leven. Een lage score geeft juist aan dat mannelijke en vrouwelijke rollen meer overlap vertonen (Hofstede 1998; Van der Lippe et al. 2010). Ook op basis van deze indicator lijkt genderongelijkheid het kleinst in Nederland (14), gevolgd door Frankrijk (43), terwijl Duitsland (66) en de Verenigde Staten (62) de 
hoogste mate van genderongelijkheid laten zien. Aan de hand van deze beperkte gegevens kunnen we de volgende hypothese formuleren.

Hypothese 2 (macrostructurele en -culturele genderongelijkheid)

De mate van genderongelijkheid in de berichtgeving over kunst en cultuur zal (2a) afnemen in de Europese landen maar licht toenemen in de Verenigde Staten gedurende de periode 1955-2005, en (2b) het grootst zijn in de Verenigde Staten en het kleinst in Nederland, waarbij Duitsland en Frankrijk een middenpositie innemen.

Tot nu toe hebben we uitsluitend aandacht besteed aan veranderingen en verschillen in de mate van genderongelijkheid in de dagbladberichtgeving over kunst en cultuur. Hierna gaan we dieper in op het soort aandacht, met name de rol van artistieke genres en verschillende typen artistieke actoren.

\section{Verschillen in seksesegregatie tussen artistieke genres}

Binnen de arbeidssociologie is veel onderzoek gedaan naar seksesegregatie, dat wil zeggen, de mate waarin mannen en vrouwen geconcentreerd zijn in verschillende beroepen (Blossfeld 1987; Charles en Bradley 2009; Reskin 1993). Een beroep is gesegregeerd wanneer de meerderheid van beoefenaars - de grens wordt veelal bij 70\% gelegd - van één sekse is, en niet van de andere (Jacobs 1989). ${ }^{2}$ We bespreken hier horizontale ('glazen muur') en verticale ('glazen plafond') seksesegregatie.

\section{Horizontale seksesegregatie}

Er is sprake van horizontale seksesegregatie wanneer de beroepenverdeling bestaande genderstereotypen bevestigt (Wharton 2012). Dat wil zeggen, wanneer vrouwen vooral beroepen vervullen waarbij de focus ligt op verzorging, sociale interactie en persoonlijke relaties, terwijl mannen instrumentele en technische beroepen vervullen. Zo zijn in vrijwel alle (westerse) landen vrouwen oververtegenwoordigd in de dienstensector, met name in beroepen als secretaresse, caissière en docent. Mannen daarentegen zijn oververtegenwoordigd in de industriële sector (Charles en Grusky 2004). Binnen het culturele veld bestaat minder consensus over hoe horizontale seksesegregatie eruitziet. Veel studies geven descriptieve overzichten van beroepsgroepen zonder expliciete vergelijking. In dit artikel beargumenteren we dat het zinvol is om beroepen te groeperen naar genre (vergelijkbaar met de domeinen in reguliere beroepsstudies) en vervolgens

2 In de literatuur worden verschillende redenen gegeven voor seksesegregatie. Zo verschillen mannelijke en vrouwelijke werknemers enerzijds wat betreft socialisatie en het effect van kinderen op de keuzes die ze maken. Anderzijds hebben mannen en vrouwen niet dezelfde kansen op de arbeidsmarkt door statistische discriminatie en de structurering van veel interne arbeidsmarkten op basis van netwerken (Wharton 2012). 
te classificeren naar het instrumentele versus expressieve karakter ervan. ${ }^{3}$ Wanneer we met deze bril de beschikbare overzichten bekijken, zien we ook een duidelijk patroon van horizontale seksesegregatie in de cultuursector.

In de onderzochte landen zijn vrouwen ondervertegenwoordigd in veronderstelde instrumentele en technische genres (zie Charles en Grusky 2004). Ten eerste vinden we horizontale seksesegregatie ( $<30 \%$ vrouwen) binnen het genre architectuur, met name in Nederland - vrouwen vormen in 2004-2006 27\% van de Ontwerpende beroepen, waaronder architecten (CBS 2011) - en de Verenigde Staten, waar in $19704 \%$ en in 2003-2005 22\% van de architecten vrouw is (NEA 1994, 2008). In Frankrijk - over Duitsland ontbreken gegevens - is er in strikte zin geen sprake van seksesegregatie, maar zijn vrouwen sterk ondervertegenwoordigd binnen architectuur: $35 \%$ is vrouw (activités d'architecture) (Cléron en Patureau 2007). Ten tweede zijn vrouwen sterk ondervertegenwoordigd in (de technische aspecten van) film, met name in Frankrijk (40\% van de categorie Activités cinématographiques et de vidéo) en de Verenigde Staten (35\% van de categorie Producers and directors), en wellicht ook in (klassieke) muziek, waar in de VS in 2003-2005 35\% en in Duitsland in 2005 33\% vrouw is. ${ }^{4}$

Vrouwen zijn daarentegen oververtegenwoordigd in stereotypische expressieve en 'emotionele' genres. Ten eerste vinden we horizontale seksesegregatie $(<30 \%$ mannen) binnen het genre dans, met name in de Verenigde Staten waar vrouwen $81 \%$ (1970) en 76\% (2003-2005) van de dansers vormen. Voor de Europese landen zijn geen gegevens beschikbaar. Ten tweede zijn vrouwen sterk oververtegenwoordigd in het genre (populaire) literatuur, met uitzondering van Duitsland. Zo is het aandeel vrouwen in Frankrijk 65\% (édition et librairie), in Nederland 63\% (Schrijvers, vertalers en overige kunstenaarsberoepen) en in de Verenigde Staten $55 \%$. We verwachten deze mate van over- en ondervertegenwoordiging in de populatie ook terug te vinden in de dagbladaandacht.

\section{Hypothese 3 (horizontale seksesegregatie - genderstereotypen)}

Vrouwen zullen ondervertegenwoordigd zijn in de berichtgeving over het genre architectuur (en in mindere mate film en klassieke muziek), en oververtegenwoordigd zijn in het genre dans (en in mindere mate literatuur).

Het ontbreken van longitudinale gegevens - bijvoorbeeld over de mate waarin stereotypische associaties zijn afgenomen - en de verschillende nationale operati-

3 Hierbij moet worden aangetekend dat nationale statistische organisaties allemaal andere genreindelingen hanteren, waardoor we alleen uitspraken kunnen doen over de grote lijnen. Omdat de aard van de werkzaamheden - niveau en richting - binnen artistieke genres sterk kan verschillen (zie ook tabel 4), hanteren we hier niet het begrip beroepsgroep maar genre. Genres definiëren we hier niet op basis van onveranderbare intrinsieke kenmerken, maar als specifieke combinaties van verwachtingen en conventies - zoals gender - die door producenten, uitvoerenden, critici en publiek herkend en gedeeld worden (Lena en Peterson 2008: 698).

4 Het is lastig om te vergelijken, aangezien de categorie Producers and directors ook theater en televisie omvat. Evenzeer is de categorie Darstellende Künstler/innen (47\% vrouwen) en Uitvoerende beroepen (34\% vrouwen) een vergaarbak van allerlei genres en beroepen. De categorie Musiker/ innen omvat ook componisten en dirigenten. 
onaliseringen van de genres maken het onmogelijk verwachtingen over trends en cross-nationale verschillen te formuleren.

\section{Verticale seksesegregatie}

We spreken van verticale seksesegregatie wanneer een van beide seksen - meestal mannen - de bestbetaalde en/of meest prestigieuze beroepen bezet. Tevens is daarbij vaak sprake van verschil in salariëring tussen mannen en vrouwen voor identieke functies (Fischer, Rojahn en Struyk 2002; Kanter 1977; Reskin en Hartmann 1988). Sterker: hoe meer een bepaald beroep gedomineerd wordt door vrouwen, hoe slechter de salariëring (Barnett, Baron en Stuart 2000) - en hoe minder statusvol het beroep vaak is (Reskin 1993: 242). Deze zogenaamde gender pay gap is sinds eind jaren zeventig kleiner geworden (Wharton 2012). De bestbetaalde beroepen in kunst en cultuur zijn in veel - maar niet alle - gevallen de door mannen gedomineerde beroepen.

In dit artikel richten we ons echter op de verschillen tussen genres gemeten naar de mate van status die ze genieten binnen een samenleving. Eerder onderzoek laat zien dat wanneer een door vrouwen gedomineerd genre in aanzien groeit, het door mannen gezien wordt als een empty field - competitie van vrouwen is immers verwaarloosbaar - en als gevolg vaak door mannen wordt gemonopoliseerd, zoals literatuur (Tuchman en Fortin 1984; Verboord, 2012), film (Bielby en Bielby 1996) of populaire muziek (Schmutz 2009). Data over de ontwikkeling van het prestige van artistieke genres zijn echter schaars, met uitzondering van een studie van Janssen, Verboord en Kuipers (2010). Zij operationaliseren het relatieve prestige van artistieke genres - vis-à-vis andere artistieke genres - via de hoeveelheid aandacht die elitekranten in Frankrijk, Duitsland, Nederland en de VS aan deze genres besteden (Janssen et al. 2010: tabel 4). Ze maken hierbij een onderscheid tussen (traditionele) 'hoge' kunst - literatuur, beeldende kunst, klassieke muziek, theater, ballet/moderne dans en architectuur - en populaire cultuur - populaire literatuur, popmuziek, populair theater, film en mode. Terwijl met name de aandacht stijgt voor popmuziek (van 2\% in 1955 naar 10\% in 2005), en in mindere mate film (van 17\% in 1955 naar 18\% in 2005), populaire fictie (van 2\% in 1955 naar 3\% in 2005) en architectuur (van 2\% in 1955 naar 4\% in 2005), daalt de aandacht voor theater (van 17\% in 1955 naar 8\% in 2005) en klassieke muziek (van 13\% in 1955 naar 9\% in 2005). We verwachten dat een toename in status zal leiden tot een toename van genderongelijkheid in de populatie en daarmee ook in de dagbladaandacht.

Hypothese 4 (verticale seksesegregatie - prestige)

Genderongelijkheid in de berichtgeving over kunst en cultuur zal toenemen in genres die groeien in aanzien (waardoor het aantal mannen in de populatie groeit), met name popmuziek, terwijl genderongelijkheid in de berichtgeving zal dalen in genres die dalen in aanzien (waardoor het aantal mannen in de populatie afneemt), zoals theater en klassieke muziek. 


\section{Verschillen in seksesegregatie tussen artistieke actoren}

We onderzoeken echter niet alleen veranderingen in genderongelijkheid in de dagbladberichtgeving over kunst en cultuur tussen genres. Ook binnen genres kunnen veranderingen en verschillen optreden op basis van de rol of functie die mannen en vrouwen vervullen. Becker (1982) onderscheidt in de arbeidsdeling van kunst en cultuur kernpersoneel en ondersteunend personeel. Onder het kernpersoneel verstaan we doorgaans de kunstenaar(s) zelf, degene aan wie speciale creatieve vaardigheden worden toegedicht ('individueel genie') en die onvervangbaar wordt geacht in de productie van het kunstwerk. Met ondersteunend personeel worden personen bedoeld die relatief eenvoudige, vervangbare functies van ambachtelijke - in plaats van creatieve - aard vervullen, zoals boekhouders, promotiepersoneel en technici.

Zoals uit de vorige paragraaf bleek hebben mannen de neiging om status te monopoliseren; dit heeft niet alleen betrekking op beroep of genre maar ook op de verschillende type actoren. Binnen bepaalde genres geldt namelijk eveneens een hiërarchie in het type actor: het beroep van regisseur is bijvoorbeeld prestigieuzer dan dat van stuntman. Het is daarom aannemelijk dat mannen de meest prestigieuze functies binnen kunstwerelden domineren, terwijl vrouwen tot lagere functies veroordeeld zijn. Inderdaad suggereren de meeste casestudies naar afzonderlijke artistieke genres dat vrouwen ondervertegenwoordigd zijn in leiderschapsposities (Hanna 1988). Om deze verwachting te onderzoeken voor onze data maken we een onderscheid - van weinig naar sterk prestigieus - tussen leken, experts, producenten, uitvoerende artiesten, scheppende artiesten en artistieke leiders (zie sectie Data en methode). We verwachten deze genderongelijkheid in de populatie ook terug te vinden in de dagbladaandacht.

\section{Hypothese 5 (reflectie van status type actor)}

Hoe statusvoller een type actor in kunst en cultuur, hoe meer genderongelijkheid in de dagbladberichtgeving over dat type actor.

Omdat er geen longitudinale en cross-nationale data beschikbaar zijn over de verdeling van mannen en vrouwen over de zojuist genoemde actoren, kunnen we niets zeggen over over- of ondervertegenwoordiging ten opzichte van het aandeel mannen en vrouwen in de verschillende functies. Wel zullen we veranderingen over de tijd en verschillen tussen landen in onze analyse betrekken.

\section{Data en methode}

Om onze onderzoeksvragen te beantwoorden maken we gebruik van data verzameld binnen het onderzoeksproject Cultural Classification Systems in Transition (zie Janssen et al. 2008). Dit betreft gegevens over de aandacht voor kunst en cultuur in telkens twee krantentitels uit Frankrijk, Duitsland, Nederland en de Verenigde Staten in de jaren 1955, 1975, 1995 en de laatste helft van 2004 en eerste helft van 2005 (hierna aangeduid als 2005). De betreffende kranten waren 
Le Monde, Le Figaro, Frankfurter Allgemeine Zeitung, Süddeutsche Zeitung, NRC Handelsblad, de Volkskrant, New York Times en Los Angeles Times. De gegevens zijn verzameld via een kwantitatieve inhoudsanalyse waarbij voor elke krantentitel per jaar 24 edities zijn gecodeerd via vier, over het jaar verspreide, geconstrueerde weken. $^{5}$ Elke weekdag wordt hierbij even vaak geselecteerd, maar niet uit hetzelfde weeknummer opdat vertekening zoveel mogelijk wordt tegengegaan (zie Riffe, Aust en Lacy 1993). De onderzoekseenheden waren de artikelen. Alle artikelen die over kunst en cultuur gingen zijn geselecteerd en vervolgens gecodeerd. ${ }^{6}$ De uiteindelijke dataset bevat derhalve ruim 18.000 artikelen over kunst en cultuur. Voor details over de steekproeftrekking en codering wordt verwezen naar Janssen et al. (2010).

In dit onderzoek is een selectie gemaakt van artikelen uit de totale dataset. Alleen artikelen die één of twee actoren bevatten zijn meegenomen (15.379 ofwel 73\%). Actoren zijn personen, groepen of organisaties die zich op enige wijze bezighouden met kunst en cultuur. Het kan gaan om uitvoerende kunstenaars (bijv. zangers, acteurs), scheppende kunstenaars (bijv. schrijvers, componisten), artistieke leiders (bijv. regisseurs, dirigenten), producenten of mediatoren (bijv. filmproducenten, galeriehouders), maar ook om beleidsmakers, vertalers, culturele fondsen of specifieke experts (bijv. advocaat, kunstopleiding) of om leken (bijv. fans). In elk artikel is vastgesteld of er één duidelijke belangrijkste actor werd opgevoerd, en of er daarnaast nog een tweede actor aandacht kreeg. Er is een intercodeursbetrouwbaarheidstest van ruim 750 artikelen uitgevoerd voor de keuze van actor 1: deze bleek voldoende betrouwbaar (Cohen's Kappa =0,809).

We onderzoeken genderongelijkheid in krantenaandacht door de verhouding van het aantal mannen en vrouwen te analyseren die als actor worden genoemd, en niet de omvang van de aandacht. Dit hebben we gedaan om een aantal redenen. Ten eerste sluit deze indicator het best aan bij de theoretische insteek: gegeven een bepaalde populatie (beroepsbevolking), welke artiesten worden succesvol? Het onderzoeken van de omvang van de aandacht zou weer andere factoren in het spel brengen (bijv. roem). Ten tweede lenen krantendata zich niet zo goed voor het focussen op de hoeveelheid aandacht (in termen van aantal woorden of aantal pagina's) omdat dit niet altijd een goede indicator is van toegekend belang door de krant (en dus niet van succes). Kranten schrijven vaak kleine stukjes over beroemde kunstenaars (nieuwsberichten), terwijl ze soms grote interviews publiceren met debutanten (die misschien daarna nooit meer aandacht krijgen). Ten derde is er een statistisch argument: wanneer we de gemiddelde hoeveelheid aandacht per geslacht berekenen verschillen de gemiddeldes niet zo sterk. Binnen de geslachten is aandacht op gelijksoortige wijze verdeeld. Het verschil zit vooral in het aantal personen dat aandacht krijgt.

5 Zondagsedities zijn gemakshalve bij de zaterdag geteld.

6 Hierbij zijn artikelen over cultuur in brede zin (bijv. religie, politiek) buitengesloten. Aandacht voor boeken en televisieprogramma's is alleen gecodeerd als het fictie betrof. Toegepaste kunst (design, mode, advertenties) telde mee als er een creator in het spel was; dus wel haute couture, maar geen nieuwe $\mathrm{H} \& \mathrm{M}$-collectie. 
Van elke actor is vastgesteld welk geslacht deze had: man, vrouw of een combinatie van beide (bijv. bij een orkest, popgroep of organisatie waarvan de samenstelling niet te achterhalen was). Als de sekse niet duidelijk was, is het opgezocht op het internet. De intercodeursbetrouwbaarheid gaf een Cohen's Kappa van 0,826. ${ }^{7}$ Vervolgens is voor elk artikel geteld hoeveel aandacht enerzijds aan mannen en anderzijds aan vrouwen is geschonken waarbij een combinatie voor beide geslachten als een half telde. Per artikel zijn dus twee variabelen berekend, en deze konden dus telkens variëren tussen 0 en 2. Daarna zijn de artikelscores geaggregeerd naar het weekniveau: dat wil zeggen dat berekend is hoeveel vrouwen en mannen per land per jaar per week in de krant stonden. Dit databestand telt in de geconstrueerde weken 128 eenheden (vier weken van acht kranten in vier jaren). Binnen dit bestand is vervolgens berekend hoe vrouwen zich ten opzichte van mannen verhouden in aandacht. Dit gemiddelde percentage per week heeft als voordeel ten opzichte van scores op het artikelniveau dat we een betrouwbaardere meting hebben (combinatie actor 1 en 2; meetellen combinaties van mannen en vrouwen), niet vastzitten aan relatief onoverzichtelijke kruistabellen om de gegevens te presenteren, en parametrische statistische testen kunnen uitvoeren.

Voor het toetsen van de verticale seksesegregatie-hypothese is de status van elke (eerste en tweede) actor gecodeerd aan de hand van de voorgaande indeling (uitvoerende kunstenaars, scheppende kunstenaars, artistiek leiders, producenten, andere experts en leken). Binnen elke categorie is vervolgens - in het geconstrueerde weekbestand - de verhouding man/vrouw berekend. De intercodeursbetrouwbaarheid (voor actor 1) gaf hier een Cohen's Kappa van 0,780. Elk artikel is eveneens gecodeerd op het artistieke genre dat (het sterkst) wordt vertegenwoordigd. Hiermee onderzoeken we horizontale seksesegregatie (instrumenteel versus expressief) en één aspect van verticale seksesegregatie (prestige van genres). Oorspronkelijk is de genreclassificatie gemeten in drie stappen: discipline (bijv. literatuur), hoofdgenre (bijv. narratief proza) en subgenre (bijv. literair proza). ${ }^{8}$ Deze variabelen zijn voor dit artikel samengevoegd tot elf genres. Als exponenten van hoge cultuur onderzoeken we literatuur, beeldende kunst, klassieke muziek, theater, ballet/moderne dans en architectuur, en binnen populaire cultuur richten we ons op populaire literatuur, popmuziek, populair theater, film en mode. Zoals al eerder beschreven in de theorie is classificatie in instrumentele en expressieve genres niet zonder haken en ogen. Hier beschouwen we architectuur (en in mindere mate film en klassieke muziek) als meer instrumenteel, en dans en mode (en in mindere mate literatuur) als meer expressief. Niet alleen vertegenwoordigen deze genres de in de theorie besproken dimensies, ook komen ze in voldoende mate voor in de krant om betrouwbare uitspraken over te doen.

We gebruiken Univariate Anova om het gemiddelde aandeel vrouwelijke kunstenaars tussen landen en jaren te vergelijken en te toetsen. Door de noodzakelijke

7 Hierbij dient te worden aangegeven dat de oorspronkelijke data in geval van twijfel wel zijn gecontroleerd, maar de hercodering niet.

8 De intercodeursbetrouwbaarheid voor de eerste twee variabelen was respectievelijk: Cohen's Kappa $=0,916$ en Cohen's Kappa $=0,828$. Voor het subgenre waren te veel uitsplitsingen om tot een goede test te komen. 
aggregatie naar weken, hebben we een relatief kleine steekproef, en voor de Verenigde Staten een ongelijk aantal onderzoekseenheden. Hierdoor voldoen niet alle variabelen aan de assumptie van homogeniteit van variantie. De resultaten van de significantietoetsen moeten daarom met enige voorzichtigheid worden geïnterpreteerd.

Tabel 2 Percentage vrouwen in dagbladaandacht voor kunst en cultuur per geconstrueerde week $(N=128)$

\begin{tabular}{llllllll}
\hline & 1955 & 1975 & 1995 & 2005 & Dui & Ned & VS \\
\hline Frankrijk & $19,1 \%$ & $14,5 \%$ & $20,6 \%$ & $22,2 \%$ & n.s. & n.s. & $* * *$ \\
Duitsland & $12,5 \%$ & $13,9 \%$ & $19,2 \%$ & $21,6 \%$ & & $\sim$ & $* * *$ \\
Nederland & $20,0 \%$ & $15,8 \%$ & $21,3 \%$ & $20,8 \%$ & & & $* * *$ \\
Verenigde Staten & $30,2 \%$ & $22,6 \%$ & $26,6 \%$ & $25,5 \%$ & & & \\
Totaal & $20,5 \%$ & $16,7 \%$ & $21,9 \%$ & $22,5 \%$ & & & \\
\hline
\end{tabular}

Geschatte marginale gemiddeldes in Anova van percentage van vrouwelijke actoren, gebaseerd op vier geconstrueerde weken per jaar per krant (noot: voor de Los Angeles Times bestaan de weken uit minder weekdagen). Significantie test Post-Hoc Bonferroni: $* * * p<.00 \mathrm{I} ; \sim \mathrm{p}<.10$

\section{Resultaten}

Longitudinale ontwikkelingen in de totale dagbladaandacht

Tabel 2 toont het aandeel dat vrouwen hebben in de berichtgeving over kunst en cultuur tussen 1955 en 2005 voor de vier onderzochte landen. We verwachtten dat vrouwen in de loop der tijd een substantiëler deel van de dagbladaandacht over kunst en cultuur zouden krijgen ( $\mathrm{H} 1 \mathrm{a}$ ) of in ieder geval in de Europese landen (H2a). Uit tabel 2 blijkt dat dit nauwelijks het geval is. Dat de jaarverschillen toch significant zijn $(\mathrm{F}(3,112)=11,74 ; \mathrm{p}=0,000)$, komt door een dip in 1975: dat jaar doorbreekt de trend in drie van de vier landen. Terwijl het aandeel vrouwen in de kunst- en cultuursectoren van de onderzochte landen steeg van ongeveer 30-35\% rond 1975 naar 40-45\% in de jaren negentig en 45-50\% in 2005 (tabel 1), blijft het aandeel in de dagbladberichtgeving in elitekranten vrij constant schommelen rond de $20 \%$ gedurende de hele onderzochte periode (tabel 2). Kortom: waar recent onderzoek laat zien dat in andere sociale domeinen genderongelijkheid nauwelijks nog afneemt (Cotter et al. 2011; IMF 2013; Ridgeway 2011: 5-6), is er in de dagbladberichtgeving over kunst en cultuur - althans in elitekranten - überhaupt nooit sprake geweest van een afname van genderongelijkheid. In vergelijking met het stijgende aandeel vrouwen in de populatie zouden we zelfs kunnen spreken van toenemende genderongelijkheid.

\section{Cross-nationale verschillen in de totale dagbladaandacht}

Tabel 2 geeft ons ook inzicht in de cross-nationale verschillen in de dagbladaandacht voor vrouwelijke - vis-à-vis mannelijke - actoren in kunst en cultuur. In 1955 was van de besproken actoren in de Europese landen tussen 12 en 20 procent vrouw; in de VS lag dit op 30 procent. Dit verklaart ook de significante 
landenverschillen $(F(3,112)=28,35 ; \mathrm{p}=0,000)$. In de loop van de tijd zijn de landenverschillen kleiner geworden (interactie-effect is significant: $F(9,112)=$ 2,62; $\mathrm{p}=0,009$ ), omdat Duitsland een inhaalslag maakte en Frankrijk licht steeg, maar in de VS werd het aandeel uit 1955 niet meer gehaald. Hypothese 2b dienen we te verwerpen, omdat - in tegenstelling tot wat de genderongelijkheidindices voorspelden - de berichtgeving in Amerikaanse elitekranten juist minder genderongelijk is dan in hun Europese tegenhangers. Hypothese 1b (afwezigheid van cross-nationale verschillen) lijkt deels (met uitzondering van het jaar 1955) bevestigd te worden.

\section{Genres en seksesegregatie}

Tabel 3 geeft het percentage vrouwen - ten opzichte van mannen - in dagbladaandacht voor hoge en populaire cultuur weer. Terwijl vrouwen gemiddeld ongeveer 20-25\% van de totale culturele verslaggeving krijgen (zie tabel 2), laat tabel 3 zien dat dit sterk verschilt tussen genres.

Als we ten eerste het algemene beeld uit tabel 3 destilleren dan zien we dat vrouwen in de dagbladaandacht voor alle genres ondervertegenwoordigd zijn. Enerzijds vinden we enige steun voor hypothese 3 (horizontale seksesegregatie). Vrouwen zijn gedurende de gehele periode sterk ondervertegenwoordigd $(<30 \%)$ in de dagbladaandacht voor architectuur (2-6\%) - het is en blijft een (stereotypisch) 'mannengenre' - en in mindere mate klassieke muziek (13-20\%) en film (13-24\%). Anderzijds vinden we ook seksesegregatie in de dagbladaandacht voor beide vormen van theater, beeldende kunst en zelfs (populaire) literatuur. En hoewel vrouwen het best vertegenwoordigd zijn in de dagbladberichtgeving over ballet/moderne dans (29-46\%) en mode (24-43\%) - dit blijven (stereotypische) 'vrouwengenres' - is er geen sprake van de verwachte oververtegenwoordiging (H3).

Ten tweede, als we ons vervolgens richten op de veranderingen in de tijd dan zien we dat het percentage vrouwen in de dagbladaandacht vooral toeneemt binnen genres die behoren tot de 'hoge' cultuur. Echter, waar hypothese 4 een toename voorspelde in de artistieke genres die in status zijn gedaald gedurende periode 1955-2005 (theater en klassieke muziek), hebben vrouwen de meeste terreinwinst geboekt in literatuur en beeldende kunst (zie tabel 3). Waren dit in de elitekranten van 1955 nog bij uitstek mannelijke bolwerken (respectievelijk $83 \%$ en $90 \%$ man), in 2005 is bijna een op de drie actoren in de literatuur vrouw, en een vijfde in de beeldende kunst. De trend in klassieke muziek vertoont - zoals voorspeld - gelijkenissen met beeldende kunst (van 13\% naar 19\%). Verder zien we dat het percentage vrouwen in de dagbladaandacht vooral sterk afneemt binnen genres die behoren tot de populaire cultuur. In de popmuziek is het percentage vrouwen sterk gezakt sinds 1955, zoals hypothese 4 al voorspelde. In dat jaar was populaire muziek nog vaak amusementsmuziek; met de komst van rockmuziek werd blijkbaar ook het genre masculiener (Frith en McRobbie 1990). Ook in film - het grootste populaire genre - zien we een daling: in 2005 is nog geen vijfde van alle actoren vrouw waar dat in 1955 nog een kwart was. In het geval van film hebben vrouwen nadeel ondervonden van de opkomst van auteur theory: het vanaf eind jaren vijftig sterker wordende geloof in de kunstwereld dat 
de regisseur de creatieve spil - en 'auteur' - van collaboratieve kunstvormen als film en theater is (Baumann 2001). ${ }^{9}$ Dit verschoof de aandacht van acteurs naar regisseurs, en in dit metier waren en zijn vrouwen ernstig ondervertegenwoordigd. In de dagbladaandacht voor beide artistieke genres zien we dus dat een stijging in prestige, zoals verwacht $(\mathrm{H} 4)$, samengaat met een daling in het percentage vrouwen. ${ }^{10}$ Populaire fictie is een uitzondering op de regel: een stijging in prestige gaat hier samen met een toename in het aandeel vrouwen in de dagbladaandacht. Ten derde zien we, hoewel we hierover geen hypothesen hebben kunnen formuleren, dat er in de dagbladaandacht voor vrouwen in kunst en cultuur veelal geen cross-nationale verschillen zijn, met name in de populaire genres. De landenverschillen constateren we vooral binnen de 'hoge' kunsten, waar - niet geheel verrassend in het licht van eerdere bevindingen - vrouwen het best vertegenwoordigd zijn in de Amerikaanse elitekranten. Mogelijk zijn Amerikaanse elitekranten ontvankelijker voor mogelijke kritiek wat betreft de representatie van vrouwen en minderheden als gevolg van de zogenaamde canon wars, die zich voornamelijk richtten op 'witte' enclaves in de 'hoge' cultuur.

9 Een belangrijke ontwikkeling vindt plaats in 1975: zowel in film als in theater stijgt het aandeel artistiek leiders ten koste van uitvoerende artiesten. Om dit te duiden gaan we terug naar het artikelenbestand en zoomen we in op de eerste (belangrijkste) actor in een artikel. We zien hier dat het percentage artistieke leiders van $19 \%$ naar $60 \%$ (film) en van $21 \%$ naar $30 \%$ (theater) gaat, terwijl acteurs hun prominentie zien afnemen van $57 \%$ naar $21 \%$ (film) en $39 \%$ naar $34 \%$ (theater).

10 De grootste landenverschillen doen zich voor binnen de hoge cultuur, waarbij geldt dat het telkens de Amerikaanse kranten betreft die het grootste percentage vrouwen bespreken. We vinden op het genreniveau geen interactie-effecten tussen land en jaar: verschillen tussen landen blijven derhalve constant. Hierbij moet worden aangetekend dat Amerikaanse kranten het sterkst betrokken zijn bij de dip in 1975: waar de Europese kranten regelmatig gestage toenames vertonen, is de ontwikkeling in de VS vaak niet lineair. 


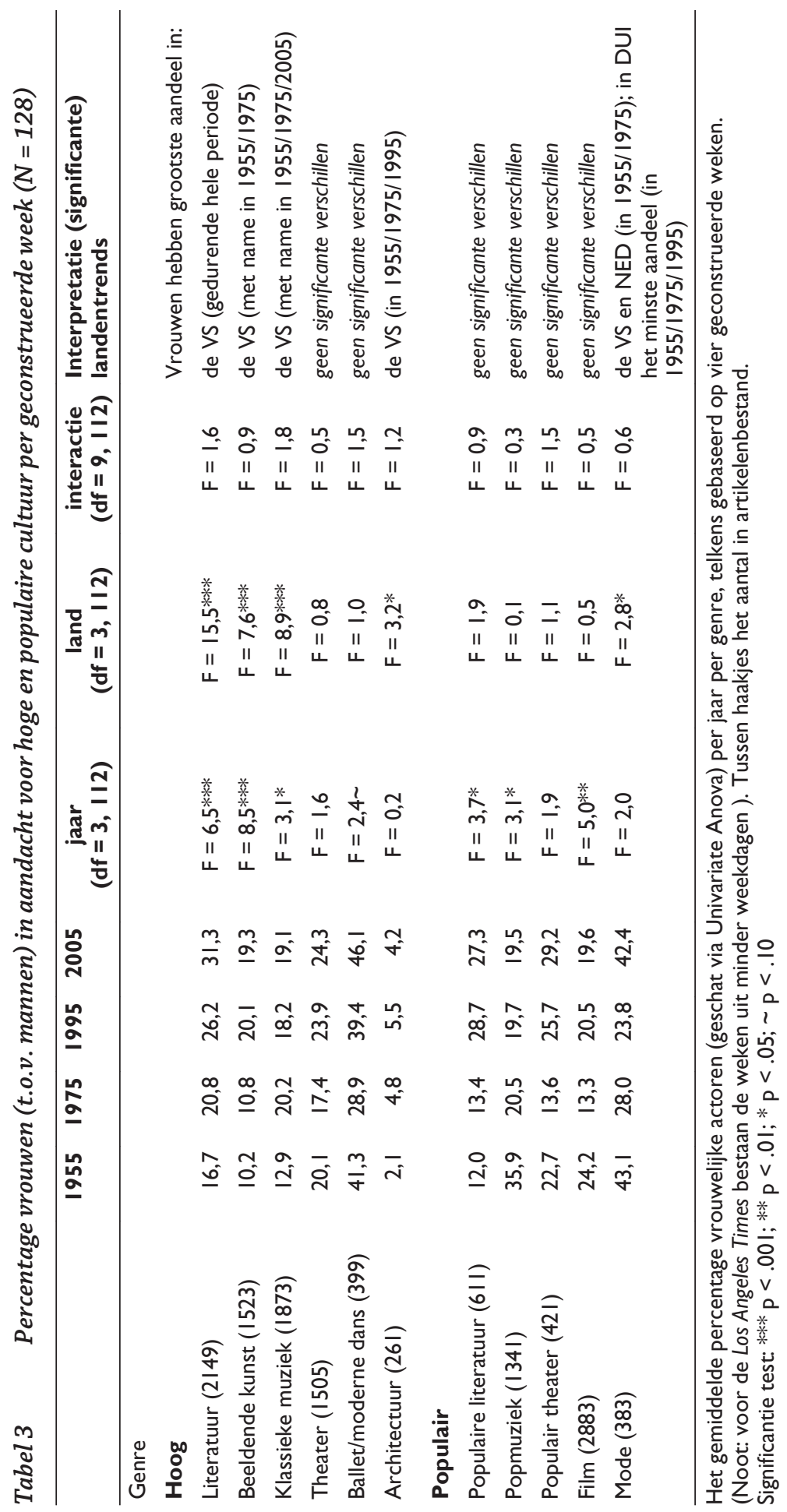




\section{Genderongelijkheid in status actoren}

Tabel 4 toont ook de sekseverdeling naar type actor, uitgedrukt in statuscategorieën. Er is slechts één categorie waarin vrouwen zijn oververtegenwoordigd, en dit is de laagste statuscategorie van leken. Uitgezonderd de neerwaartse uitschieter in 1975, nemen vrouwen hier voortdurend een aandeel van ongeveer $60 \%$ of meer in. Naarmate de status echter toeneemt, neemt het aandeel vrouwen in de dagbladaandacht voor kunst en cultuur af, zoals we voorspelden (H5). Uiteraard kan gedebatteerd worden over de exacte statusverhoudingen tussen typen actoren, maar duidelijk is dat actoren die zich bezighouden met artistieke leiding relatief het vaakst man zijn (in 2005 slechts 9\% vrouwen), gevolgd door producenten (tussen 6 en 12\%), en scheppende artiesten (tussen de 8 en 13\%). Kunstgerelateerde experts en uitvoerende artiesten zijn gemiddeld wat vaker van het vrouwelijk geslacht; na 1995 ongeveer een kwart. De trendcijfers laten zien dat er hier wel een en ander verandert. Tegenover een daling van het percentage vrouwen onder uitvoerende artiesten staat een sterke stijging van het aandeel vrouwelijke experts en de - weliswaar lichte - toename van het aandeel vrouwen onder scheppende artiesten en artistiek leiders. Deze trends zijn significant. Net als bij de genreverschillen nemen de Amerikaanse elitekranten doorgaans het voortouw in de afname in genderongelijkheid.

Een mogelijke verklaring voor de gevonden ontwikkelingen biedt de doorbraak van de eerder genoemde auteur theory. De rol van artistiek leider (regisseur) was echter in hoge mate een door mannen vervulde rol. Omdat het aandeel vrouwelijke filmregisseurs in de krant tussen 1955 en 1975 slechts van 2\% naar 4\% steeg (wordt $9 \%$ in 2005), en in theater op $7 \%$ blijft staan (wordt $21 \%$ in 2005), werden minder vrouwen besproken. De stijging van de status van het genre dat met de toegenomen aandacht voor regisseurs gepaard ging (Baumann 2001), verslechterde derhalve de positie van vrouwen. Met name de Amerikaanse kranten 'intellectualiseerden' na 1955: zowel de NYT als de LAT schreef in 1955 nog vele korte nieuwsitems over film- en Broadway-sterren; dit werd hierna stukken minder. Overigens moet hierbij wel worden aangetekend dat ook onder film- en theateracteurs in 1975 vrouwen relatief minder vaak als eerste actor in een krantenstuk werden genoemd dan in 1955 en 1995. Of dit betekent dat de jaren zeventig in het algemeen geen gunstig decennium voor vrouwenemancipatie in de kunsten was, is uiteraard op grond van één jaar moeilijk te zeggen. Wel is het opvallend dat deze geringe aandacht zich in meer landen en meer genres voordeed. 


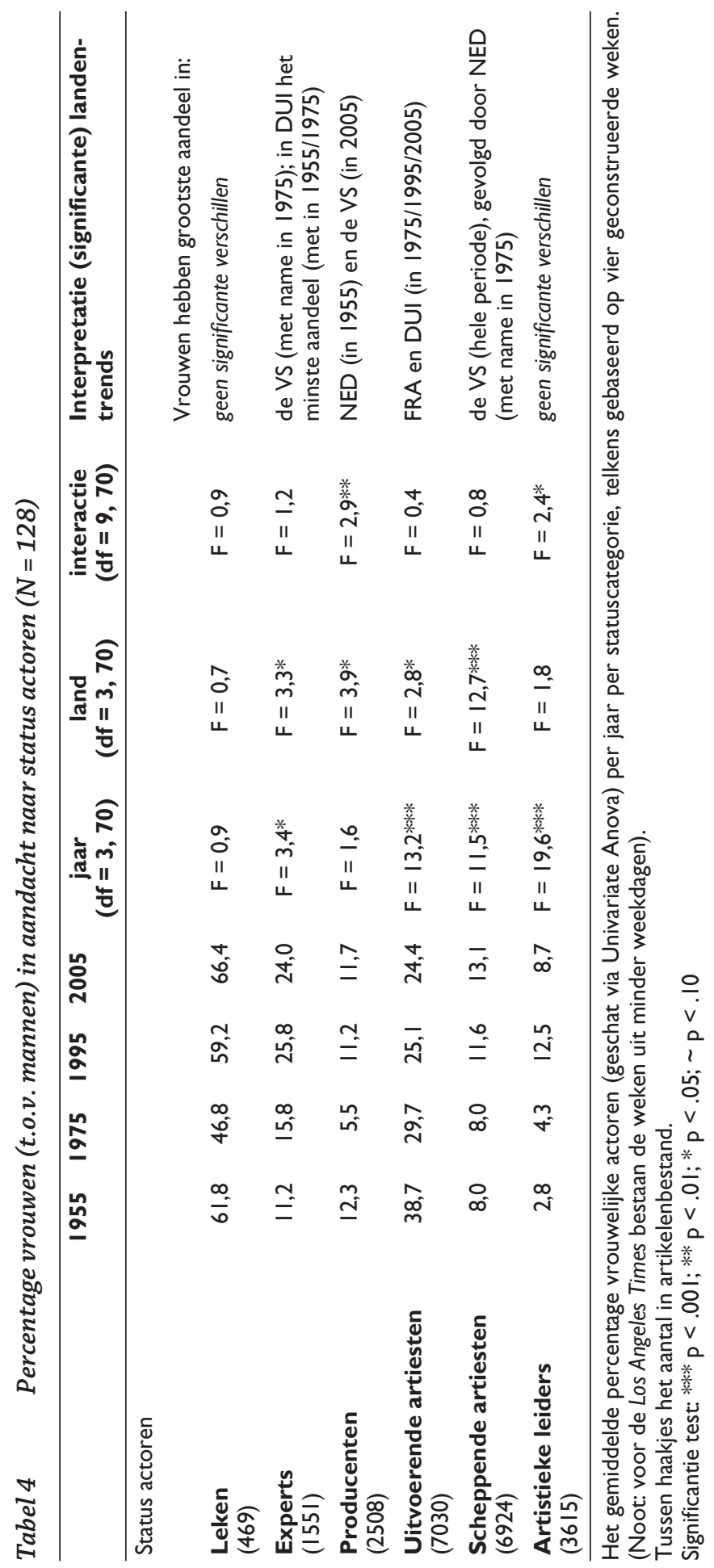




\section{Conclusie en discussie}

In dit artikel is onderzocht in welke mate en op welke manier genderongelijkheid is veranderd in de dagbladberichtgeving over kunst en cultuur voor de landen Frankrijk, Duitsland, Nederland en de Verenigde Staten, in de periode 1955-2005. De resultaten stemmen niet vrolijk. Ten eerste is er in de afgelopen vijf decennia in geen enkel van de onderzochte landen ook maar bij benadering gelijkheid bereikt in de aandacht voor vrouwen in de kunsten. In grove lijnen is anno 2005 (het laatste peiljaar) ongeveer 20 tot 25\% van de artikelen gewijd aan vrouwen, vergelijkbaar met het peiljaar 1955 (13-30\%). En dat terwijl het percentage vrouwen werkzaam in kunst en cultuur is gestegen in elk van de vier onderzochte landen van ongeveer $30-35 \%$ in 1975 tot $45-50 \%$ in 2005 . Er was echter geen sprake van reflectie van de populatie of een duidelijk verband met maatschappelijke ongelijkheid in het algemeen. Een mogelijke verklaring zou kunnen zijn dat het aandeel vrouwen dat daadwerkelijk succesvol is in de kunst en cultuur niet is toegenomen, waardoor vrouwen nog steeds weinig aandacht in dagbladen krijgen (Coulangeon, Ravet en Roharik 2005; Dowd et al. 2005; Verboord 2012).

Ten tweede vonden we verrassend weinig cross-nationale verschillen. De mondiale trend laat vooral stagnatie zien in de dagbladaandacht voor vrouwen in kunst en cultuur. Opvallend is dat juist de Amerikaanse elitekranten minder - in plaats van meer, zoals voorspeld op basis van maatschappelijke genderongelijkheidindices - ongelijk berichten over mannen en vrouwen in kunst en cultuur dan de Europese dagbladen. Wellicht wijken de onderzochte Amerikaanse elitekranten - en de kunstsector in het algemeen - wat betreft waardepatroon sterk af van de gemiddelde, meer traditioneel ingestelde Amerikaan (Benson 2006: table 1), waardoor de maatschappelijke genderongelijkheid in de Verenigde Staten niet zo sterk samenhangt met ongelijkheid in dagbladberichtgeving over kunst en cultuur. Tevens worden de landenverschillen gedurende de periode 1955-2005 kleiner. Mogelijk ligt de verklaring in de toegenomen globalisering van kunst en cultuur en de internationale oriëntatie van Europese elitekranten (Janssen et al. 2008).

Ten derde zijn vrouwen ondervertegenwoordigd in alle artistieke genres wat betreft de dagbladberichtgeving over kunst en cultuur; we vonden echter wel duidelijke verschillen tussen de genres. In zeker mate is er sprake van horizontale seksesegregatie in de berichtgeving. Zoals verwacht blijven architectuur - en in mindere mate klassieke muziek en film - grotendeels stereotypische 'mannengenres', maar dit geldt ook voor beide vormen van theater, beeldende kunst en zelfs (populaire) literatuur. Moderne dans en mode blijven stereotypische 'vrouwengenres', maar zonder dat er sprake is van oververtegenwoordiging.

Ten vierde zagen we dat het percentage vrouwen vooral toeneemt in de dagbladaandacht voor genres die behoren tot de 'hoge' cultuur. Dit gold voor genres waarvan empirisch is aangetoond dat deze minder prestigieus zijn geworden gedurende de periode 1955- 2005 - theater en klassieke muziek (Janssen et al. 2010) - maar ook voor literatuur en beeldende kunst. Verder laten de resultaten zien dat het percentage vrouwen in de dagbladaandacht sterk afneemt binnen 
genres die behoren tot de populaire cultuur, met name binnen in status gestegen genres als popmuziek en film. In het geval van populaire literatuur kan verondersteld worden dat de feminisering van zowel de vraag als het aanbod van fictieboeken (zie bijv. Griswold 2008; Verboord 2011) impact heeft gehad. Opmerkelijk is dat de populaire kunsten de opgang van vrouwelijke kunstenaars - als geheel - niet noemenswaardig hebben gestimuleerd. De empty field-theorie, waarin een hogere status van een genre geassocieerd wordt met een grotere instroom van mannen, wordt in dit onderzoek dus slechts ten dele bevestigd. Het ontbreken van goede (non-media-)indicatoren om de veranderende status van artistieke genres - en daarmee verticale seksesegregatie in de populatie - te meten maakt het moeilijk om te zeggen in hoeverre er sprake is van bias bij de critici of een verandering in de populatie. Toekomstig onderzoek zal dit moeten uitwijzen.

Ten slotte vinden we sterk bewijs voor het belang van de status van het type actor. De ondervertegenwoordiging van vrouwen in leidinggevende functies - of dit nu artistiek leiderschap of productie/distributietaken betreft - vormt een ernstige belemmering voor media-aandacht. Zeker nu kranten in toenemende mate de context van de kunsten zijn gaan bespreken. Maar daarnaast lijkt er toch ook sprake te zijn van institutioneel gevormde ongelijkheden die binnen elke generatie worden gereproduceerd. Dit betreft voornamelijk de aanbodzijde: binnen een genre lijken conventies te bestaan die meer gelijkwaardige rolvervullingen tegenhouden. Architecten en filmregisseurs blijven vooral mannen, terwijl binnen ballet en mode vrouwen veel vaker doorstromen naar artistiek leiderschap. Meer onderzoek naar genderongelijkheid binnen genres blijft derhalve geboden. Zo zou nieuw onderzoek moeten pogen de status van beroepen en van genres beter van elkaar te onderscheiden. Ook dient de verdeling van type actoren in de populatie en in de dagbladaandacht verder te worden onderzocht. Is hier sprake van 'simpele' reflectie of spelen genderstereotypen ook op het niveau van de berichtgeving een rol?

Ondanks het feit dat ons onderzoek gebaseerd is op een grote hoeveelheid gegevens en - naar onze mening - een betrouwbaar beeld schetst van de ontwikkeling van de aandacht voor vrouwelijke kunstenaars in elitekranten, is er een aantal beperkingen aan te wijzen. Ten eerste zijn onze metingen niet altijd optimaal om de aangehaalde theorieën te toetsen. Ten tweede analyseren we een beperkte hoeveelheid jaren, landen en geconstrueerde weken. De significantietoetsingen van trends en landenverschillen dienen derhalve met voorzichtigheid te worden geïnterpreteerd. Ten derde laat ons onderzoek niet zien hoe er geschreven wordt over vrouwen: ook dit is een belangrijk punt voor verder onderzoek.

We willen echter benadrukken dat de acht onderzochte kranten behoren tot de toonaangevende media in de vier geselecteerde landen. Wellicht is hun impact op de samenleving in de loop der jaren afgenomen door verminderde oplagecijfers, maar ze blijven relatief belangrijk voor de opinievorming rondom cultuur (bijv. Verboord 2010). Niettemin zou toekomstig onderzoek de vergelijking kunnen zoeken tussen kranten, televisieprogramma's (in Nederland bijvoorbeeld De Wereld Draait Door) en internetsites. Op deze manier kunnen we in de toekomst 
nog beter uitspraken doen over de ontwikkeling van vrouwenemancipatie in de kunst en cultuur en de rol van de media hierin.

\section{Literatuur}

Barnett, W.P., J.N. Baron en T.E. Stuart (2000) Avenues of attainment: Occupational demography and organizational careers in the Californian civil service. American Journal of Sociology, 106(1): 88-144.

Baumann, S. (2001) Intellectualization and art world development: Film in the United States. American Sociological Review, 66(3): 404-426.

Baumann, S. (2007) A general theory of artistic legitimation: How art worlds are like social movements. Poetics, 35(1): 47-65.

Becker, H.S. (1982) Art worlds. Los Angeles: University of California Press.

Benson, R. (2006) News media as a "journalistic field": What Bourdieu adds to New Institutionalism, and vice versa. Political Communication, 23: 187-202.

Berkers, P. (2012) Gendered scrobbling: Listening behaviour of young adults on Last.fm. Interactions: Studies in Communication \& Culture, 2(3): 279-296.

Berkers, P. en M. Eeckelaer (2014) Rock and roll or rock and fall? Gendered framing of the rock and roll lifestyles of Amy Winehouse and Pete Doherty in British broadsheets. Journal of Gender Studies, 23(1): 3-17.

Berkers, P., S. Janssen en M. Verboord (2011) Globalization and ethnic diversity in Western newspaper coverage of literary authors: Comparing developments in France, Germany, the Netherlands, and the United States, 1955 to 2005. American Behavioral Scientist, 55(5): 624-641.

Bielby, D.D. en W.T. Bielby (1992) Cumulative versus continuous disadvantage in an unstructured labor market: Gender differences in the careers of television writers. Work and Occupations, 19(4): 366-386.

Bielby, D.D. en W.T. Bielby (1996) Women and men in film: Gender inequality among writers in a culture industry. Gender \& Society, 10(3): 248-270.

Blossfeld, H. (1987) Labor-market entry and the sexual segregation of careers in the Federal Republic of Germany. American Journal of Sociology, 93(1): 89-118.

Bourdieu, P. (1993) The field of cultural production. Cambridge: Polity Press.

Cameron, S. (2003) The political economy of gender disparity in musical markets. Cambridge Journal of Economics, 27(6): 905-917.

Caven, V. (2004) Constructing a career: Women architects at work. Career Development International, 9(5): 518-531.

CBS, Centraal Bureau voor de Statistiek (2007) Kunstenaars in Nederland. Voorburg/ Heerlen: Centraal Bureau voor de Statistiek.

CBS, Centraal Bureau voor de Statistiek (2011) Kunstenaars in breder perspectief: Kunstenaars, kunstopleiding en arbeidsmarkt. Den Haag: Centraal Bureau voor de Statistiek.

Charles, M. en K. Bradley (2009) Indulging our gendered selves? Sex segregation by field of study in 44 countries. American Journal of Sociology, 114(4): 924-976.

Charles, M. en D.B. Grusky (2004) Occupational ghettos: The worldwide segregation of women and men. Stanford: Stanford University Press.

Cléron, É. en F. Patureau (2007) L'emploi dans le secteur culturel en 2005. Paris: Département des études, de la prospective et des statistiques. (http://www. culturecommunication.gouv.fr/content/download/38381/309435/file/archiv_cc2007 -7_emploicult_site.pdf)

Connell, R. (2009) Gender: In world perspective. Cambridge: Polity Press. 
Cotter, D., J.M. Hermsen en R. Vanneman (2011) The end of the gender revolution? Gender role attitudes from 1977 to 2008. American Journal of Sociology, 117(1): 259-289.

Coulangeon, P., H. Ravet en I. Roharik (2005) Gender differentiated effect of time in performing arts professions: Musicians, actors and dancers in contemporary France. Poetics, 33(5-6): 369-387.

Dowd, T.J., K. Liddle en M. Blyler (2005) Charting gender: The success of female acts in the US mainstream recording market 1940-1990. In: C. Jones, P.H. Thornton (red.) Transformation in cultural industries (Research in the sociology of organizations, 23), Bingley: Emerald Group, 81-123.

Dyke, J. Van (1996) Gender and success in the American dance world. Women's International Forum, 19(5): 535-543.

Epstein, C.F. (1988) Deceptive distinctions: Sex, gender, and the social order. New Haven: Yale University Press.

Federal Reserve Economic Data (2013) Women's share of the labor force in Germany. Op 28 augustus 2014 geraadpleegd op http://research.stlouisfed.org/fred2/series/ DEULFWNA.

Fischer, A., K. Rojahn en I. Struyk (2002) Het glazen plafond in de culturele sector: Feiten en verklaringen. Amsterdam: Universiteit van Amsterdam.

Fohrbeck, K. en A. Wiesand (1975) Der Künstler-Report. Munich: Hanser.

Frith, S. en A. McRobbie (1990) Rock and sexuality. In: S. Frith en A. Goodwin (red.) On Record: Rock, pop and the written word. London: Routledge, 371-389.

Gauntlett, D. (2008) Media, gender and identity. London: Routledge.

Griswold, W. (1981) American character and the American novel: An expansion of reflection theory in the sociology of literature. American Journal of Sociology, 86(4): 740-765.

Griswold, W. (2008) Regionalism and the reading class. Chicago: University of Chicago Press.

Guerrilla Girls (1995) Confessions of the Guerrilla Girls. New York: HarperPerennial.

Hanna, J.L. (1988) Dance, sex, and gender: Signs of identity, dominance, defiance, and desire. Chicago: University of Chicago Press.

Hofstede, G. (1998) Masculinity and femininity: The taboo dimension of national cultures. Thousand Oaks: Sage.

Hyde, J.S. (2005) The gender similarities hypothesis. American Psychologist, 60(6): 581-592.

IAB (2013) Institut für Arbeitsmarkt- und Berufsforschung der Bundesagentur für Arbeit, Berufe im Spiegel der Statistik. Op 2 augustus 2013 geraadpleegd op http://bisds. infosys.iab.de/.

IMF, International Monetary Fund (2013) Women, work, and the economy: Macroeconomic gains from gender Equity. Genève: International Monetary Fund (https://www. imf.org/external/pubs/ft/sdn/2013/sdn1310.pdf).

INSEE, Institut National de la Statistique et des Etudes Economiques (2008) Les fonctions culturelles: des dynamiques régionales différenciées qui accompagnent le boom de l'emploi. Economie Lorraine $n^{\circ} 127$ Bis.

INSEE, Institut National de la Statistique et des Etudes Economiques (2009) Les domains culturels: spectacles vivant et activités artistiques. L'Emploi Culturelle en Ansace, 15.

Jacobs, J.A. (1989) Revolving doors: Sex segregation and women's careers. Stanford: Stanford University Press.

Janssen, S. (1997) Reviewing as social practice. Poetics, 24(5): 275-297.

Janssen, S., G. Kuipers en M. Verboord (2008) Cultural globalization and arts journalism: The international orientation of arts and culture coverage in American, Dutch, French and German newspapers 1955-2005. American Sociological Review, 73(5): 719-740. 
Janssen, S., M. Verboord en G. Kuipers (2010) Classificaties in de kunstjournalistiek: Hoge en populaire cultuur in Europese en Amerikaanse elitekranten 1955-2005. Sociologie, 6(4): 51-77.

Kanter, R.M. (1977) Men and women of the corporation. New York: Basic Books.

Lena, J.C. en R.A. Peterson (2008) Classification as culture: Types and trajectories of music genres. American Sociological Review, 78(5): 697-718.

Lincoln, A.E. en M.P. Allen (2004) Double jeopardy in Hollywood: Age and gender in the careers of film actors, 1926-1999. Sociological Forum, 19(4): 611-631.

Lippe, T. van der, J. de Ruijter, E. de Ruijter en W. Raub (2011) Persistent inequalities in time use between men and women: A detailed look at the influence of economic circumstances, policies, and culture. European Sociological Review, 27(2): 164-179.

MacLeod, B.A. (2001) Women performing music. London: McFarland.

NEA, National Endowment of the Arts (1994) Trends in artist occupations 1970-1990. NEA Research Division Report 29.

NEA, National Endowment of the Arts (2008) Women artists: 1990-2005. NEA Research Note 96.

Rees, K. van (1983) How a literary work becomes a masterpiece. Poetics, 12(4-5): 397-417.

Reskin, B.F. (1993) Sex segregation in the workplace. Annual Review of Sociology, 19: 241-270.

Reskin, B.F. en H.I. Hartmann (1988) Women's work, men's work: Sex segregation on the job. Washington: National Academy Press.

Ridgeway, C.L. (2011) Framed by gender: How gender inequality persists in the modern world. New York: Oxford University Press.

Ridgeway, C.L. en L. Smith-Lovin (1999) The gender system and interaction. Annual Review of Sociology, 25: 191-216.

Riffe, D., C.F. Aust en S.R. Lacy (1993) The effectiveness of random, consecutive day and constructed week sampling in newspaper content analysis. Journalism \& Mass Communication Quarterly, 70(1): 133-139.

Rosen, S. (1981) The economics of superstars. The American Economic Review, 71(5): 845-858.

Schmutz, V. (2009) Social and symbolic boundaries in newspaper coverage of music, 1955-2005: Gender and genre in the US, France, Germany, and the Netherlands. Poetics, 37(4): 298-314.

Schmutz, V. en A. Faupel (2010) Gender and cultural consecration in popular music. Social Forces, 89(2): 685-707. Op 2 augustus 2013 geraadpeegd op Statline, http://statline. cbs.nl/.

Tuchman, G. en N.E. Fortin (1984) Fame and fortune: Edging women out of the great literary tradition. American Journal of Sociology, 90(1): 72-96.

Verboord, M. (2010) The legitimacy of book critics in the age of the Internet and omnivorousness: Expert critics, Internet critics and peer critics in Flanders and the Netherlands. European Sociological Review, 26(6): 623-637.

Verboord, M. (2011) Cultural products go online: Comparing the Internet and print media on distributions of gender, genre and commercial success. Communications. The European Journal of Communication Research, 36(4): 441-462.

Verboord, M. (2012) Female bestsellers: A cross-national study of gender inequality and the popular-highbrow culture divide in fiction book production, 1960-2009. European Journal of Communication, 27(4): 395-409.

Verenigde Naties (2011) Human development report 2011. New York: Consolidated Graphics. 
Von Bonin, W. (1992) Künstlerinnen: Die Guerilla Girls. Emma, 1 januari 1992. (http:// www.emma.de/artikel/kuenstlerinnen-die-guerilla-girls-266238).

Weijts, C. (2006) Guerrilla Girls bestormen musea. Mare, 22, 2 maart 2006. (http://www. mareonline.nl/0506/22/09.html).

West, C. en D.H. Zimmerman (1987) Doing gender. Gender \& Society, 1(2): 125-151.

Wharton, A.S. (2012) The sociology of gender. Malden: Blackwell. 